\title{
Downregulation of microRNA-100 protects apoptosis and promotes neuronal growth in retinal ganglion cells
}

Ning Kong ${ }^{1,2}$, Xiaohe $\mathrm{Lu}^{1^{*}}$ and Bin $\mathrm{Li}^{2}$

\begin{abstract}
Background: Retinal ganglion cells (RGCS) are preferentially lost in glaucoma or optic neuritis. In the present study, we investigated the protective effect of mircoRNA 100 (miR-100) against oxidative stress induced apoptosis in RGC-5 cells.

Results: Rat RGC-5 cells were cultured in plates and $\mathrm{H}_{2} \mathrm{O}_{2}$ was added to induce oxidative stress. TUNEL assay and qRT-PCR showed $\mathrm{H}_{2} \mathrm{O}_{2}$ induced apoptosis and up-regulated miR-100 in a dose-dependent manner in RGC-5 cells. Conversely, lentiviral-mediated miR-100 down-regulation protected $\mathrm{H}_{2} \mathrm{O}_{2}$ induced apoptosis, promoted neurite growth and activated AKT/ERK and TrkB pathways through phosphorylation. Luciferase assay confirmed that IGF1R was directly regulated by miR-100 in RGC-5 cells, and siRNA-mediated IGF1R knockdown activated AKT protein through phosphorylation, down-regulated miR-100, therefore exerted a protective effect on RGC-5 apoptosis.

Conclusion: Down-regulating miR-100 is an effective method to protect $\mathrm{H}_{2} \mathrm{O}_{2}$ induced apoptosis in $\mathrm{RGC}-5$ cells, possible associated with IGF1R regulation.
\end{abstract}

Keywords: Retinal ganglion, miR-100, Oxidative stress, Apoptosis, IGF-1

\section{Background}

Retinal ganglion cells (RGCs) are a group of specialized sensory neurons in the central nervous system, rested in the inner layer of the retina. RGCs capture visual signals from bipolar and amacrine cells through the photoreceptors on the outer retina, and electrically transmit that information to the brain. In glaucoma patients, increased intraocular pressure damage the cell bodies as well as the axons of RGCs, resulting in permanent and irreversible blindness [1]. The degeneration of retina in glaucoma patients is often accompanied by apoptosis of RGCs, which may be caused by excitotoxicity, hypoxia, or oxidative stress [2-4]. Many of the molecular pathways, including Akt, ERK, insulin-like growth factor 1 (IGF-1) and its receptor IGF1R, brain-derived neurotrophic factor (BDNF) and its tyrosine kinase receptor TrkB, repulsive guidance molecule, RGMa and its receptor neogenin, are actively involved in the development or the protection/

\footnotetext{
* Correspondence: libin_bin@aol.com

'Department of Ophthalmology, Zhujiang Hospital, Southern Medical

University, Guangzhou 510280, Guangdong Province, China

Full list of author information is available at the end of the article
}

regeneration of sensory neurons including RGC [5-13]. However, though many of the molecular pathways have been identified to protect RGCs from degeneration and induce optical nerve regeneration [14], the exact mechanism of RGC damage, or feasible clinical strategy for RGC regeneration are largely unknown.

MicroRNAs (miRNAs) are a group of noncoding RNAs with $\sim 20$ nucleotides, that inhibit endogenous gene expression through translational cleavage [15]. In both animal and human visual systems, miRNAs have been demonstrated to be involved in various aspects of retina development, including retinogenesis, retinal homeostasis, or retinal damage. For example, studies in mutant mice have shown that, miR-183/96/182 clusters and miR132/212 were essential for the synaptic development in retina [16-18], and miR-124 was critical for the maturation of cone cells [19] in retina. Study also showed that miR-218 inhibits Robo/Slit pathway to maintain normal vascular function in retina [20]. In retinal ganglion cells, a recent study specifically demonstrated that miR-132 was involved in BDNF-mediated retinal ganglion axonal branching and maturation [21]. Specifically, emerging evidences 
demonstrate that miRNAs are highly associated with many aspects of retinal degeneration [22,23], yet the exact mechanisms of miRNAs on regulating retinal apoptosis or degeneration are largely unknown. MicroRNA-100 (miR-100), a member of miR-99 family (including miR99a, miR-99b, miR-100), is a key apoptotic regulator in various cell types [24,25]. In retina, miR-100 was found to be associated with diabetic retinopathy, a common retinal disease leading to total blindness [26]. However, the function role of miR-100 in mediating retinal development or pathology remains elusive.

In the present study, we used an in vitro culture system to induce oxidative stress by $\mathrm{H}_{2} \mathrm{O}_{2}$ application in rat ganglion cell line RGC-5 cells. We found that microRNA 100 (miR-100) was specifically upregulated in RGC-5 cells upon apoptosis. We then investigated the anti-apoptosis effect of down-regulating miR-100, as well as the association between miR-100 down-regulation and apoptosisrelated pathways, Akt/ERK/TrkB and IGF1R, in retina ganglion cells.

\section{Methods}

Ethics statement

All experimental procedures are approved by the Ethics Committee at Guangzhou Panyu Central Hospital, Guangzhou, China.

\section{RGC- 5 cell culture}

The RGC-5 cell line, a transformed retinal ganglion progenitor cell line originally generated by Dr. N. Agarwal at the University of North Texas Health Science in the United States, was obtained from the Zhonghan Ophthalmic Center in Guangzhou, China. RGC-5 cells were cultured in low-glucose Dulbecco's modified Eagle's medium (DMEM, Gibco, USA) containing 10\% fetal calf serum (FBS, Sigma Aldrich, USA), $100 \mathrm{U} / \mathrm{ml}$ penicillin and $100 \mu \mathrm{g} / \mathrm{ml}$ streptomycin in a $37^{\circ} \mathrm{C}$ tissue culture chamber supplied with $95 \%$ air and $5 \% \mathrm{CO}_{2}$. The RGC-5 cells were passaged by trypsinization every 2 to 3 days.

\section{Apoptosis induction}

To induce apoptosis in RGC-5 cell, an oxidative stress model was used. Briefly, RGC-5 cells were seeded into 24well plates at concentration of $1 \times 10^{5} / \mathrm{cm}^{2}$. Various concentrations of hydrogen peroxide $\left(\mathrm{H}_{2} \mathrm{O}_{2}\right)(100 \mu \mathrm{m} \sim 1000 \mu \mathrm{m})$ were added into the culture for 24 hours.

\section{TUNEL assay}

RGC-5 cells were fixed with $4 \%$ paraformaldehyde (PFA) in phosphate-buffered saline (PBS) for $20 \mathrm{~min}$, and permeabilized with $1 \%$ Triton X-100 for 10 min. TUNEL staining was conducted with an In-Situ Apoptosis Detection Kit (Chemicon, USA) according to the manufacturer's protocol. A primary antibody against neural progenitor marker Brn3a (1:500, Santa Cruz, USA) was also used to identify RGC-5 cells. Imaging was done on an Axiovert 200 fluorescence microscope (Carl Zeiss, Germany). For each condition, $5 \sim 8$ regions ( $\sim 100$ cells per region) were randomly taken for analysis. The percentage of TUNELpositive RGC- 5 cells were calculated against all brn3a positive cells and normalized to the control condition. Each experiment was repeated at least 3 times.

\section{RNA isolation and quantitative real-time reverse transcription-PCR (qRT-PCR)}

Cultured RGC-5 cells were trypsinized and collected. RNA and miRNA fractions were then extracted using a Trizol RNA purification Kit according to manufacturer's instruction (Qiagen, USA). Total RNA concentrations were confirmed with a NanoDrop ND-1000 spectrophotometer (NanoDrop Technologies, USA) at 260 and $280 \mathrm{~nm}$ (A260/280), and analyzed with an Agilent 2100 Bioanalyzer (Agilent Technologies, USA). Quantitative realtime reverse transcription-PCR (qRT-PCR) was performed by a TaqMan miRNA Assay according to manufacturer's instruction (Applied Biosystems, USA). The amplification conditions were 35 cycles of $20 \mathrm{~s}$ at $97^{\circ} \mathrm{C}$ and $2 \mathrm{~min}$ at $56^{\circ} \mathrm{C}$. The internal housing keeping genes were U6 for miR-100, and GAPDH for insulin-like growth factor 1 receptor (IGF1R) respectively.

\section{Lentivirus transfection}

The oligonucleotides of rno-miR-100 inhibitor, rno-miR100 mimics and non-specific control were puchased from Ribo-Bio (Ribo-Bio, Shanghai, China). The coding sequences were then amplified and cloned into $\mathrm{pCDH}-$ CMV-MCS-EF1-coGFP constructs (System Biosciences, USA) to construct miR-100 inhibitor vector (miR100Inhibitor), miR-100 mimics vector (miR100-mimics) and non-specific miRNA vector (miR-NC). The lentiviral vectors were co-transfected with pPACK packaging plasmid into $293 \mathrm{~T}$ cells. The viral products were then collected and titered. The transfection of miR-100Inhibitor or miR-NC into RGC-5 cells was conducted by a Lipofectamine 2000 reagent according to manufacturer's recommendation (Invitrogen, USA). The culture medium was changed 24 hours after transfection.

\section{Immunocytochemistry}

RGC-5 cells were fixed with $10 \%$ neutral-buffered formalin containing 5\% methanol for 10 minutes, followed by washing in PBS $(3 \times 10$ mins). The cells were then treated with permeabilization solution containing $0.3 \%$ trition X-100 and 3\% horse serum in PBS for 30 minutes, followed by washing PBS $(3 \times 10$ mins $)$. The cells were incubated with primary antibody of Thy-1 (1:250 in permeabilization solution, Sigma Aldrich, USA) at $4^{\circ} \mathrm{C}$ overnight in a humidified box. On second day, cells were 
incubated with secondary antibody of Alexa-Fluor 488 (1:500 in PBS) for 12 hours. RGC-5 cells were also stained with the fluorescent nuclear binding label 4,6diamidino-2-phenylindole (DAPI; $500 \mathrm{ng} / \mathrm{mL}$ ).

\section{Western blot analysis}

RGC-5 lysates of were prepared with a lysis buffer containing $50 \mathrm{mM}$ Tris (pH 7.6), $150 \mathrm{mM} \mathrm{NaCl}, 1 \mathrm{mM}$ EDTA, $10 \%$ glycerol, and $0.5 \% \mathrm{NP}-40$ and protease inhibitor cocktail (Invitrogen, USA). The total protein were then separated on $10 \%$ SDS-PAGE gel and transferred to the nitrocellulose membranes. We used primary antibodies against, Thy-1 (1:2000, Santa Cruz Biotechnology, USA), ERK1/2 (1:1000, Cell Signaling Technology, USA), phospho-Erk1/2 (pERK1/2, 1:2000, Cell Signaling Technology, USA), PI3k3 /serine-threonine kinase (AKT, 1:1000, Cell Signaling Technology, USA), phosphor-AKT (pAKT, 1:1000, Cell Signaling Technology, USA), TrkB (1:1000, Cell Signaling Technology, USA), phosphorylated TrkB (1:200, Cell Signaling Technology, USA) and IGF1R (1:200, Santa Cruz Biotechnology, USA). Horseradish peroxidase-conjugated secondary antibodies (Bio-Rad, USA) were used and Actin was used as internal control. The western blots were visualized with an enhanced chemiluminesence system (Amersham Biosciences, USA) according to the manufacturer's protocol. Band intensities normalized to the total protein immuno-precipitation under each control condition and quantified with an ImageJ software (NIH, USA).

\section{Luciferase reporter assay}

RGC-5 cells were collected and regular PCR was performed to amplify the cDNAs of wild-type 3'-UTR of IGF1R. A mutant (MT) 3'-UTR of IGF1R (with modified binding site to rno-miR-100, Figure 1A) was also created by Site-Directed Mutagenesis Kit (SBS Genetech, China). The amplified cDNAs were then inserted into a pmiRREPORT luciferase reporter vector (Ambion, USA) to construct Luc- IGF1R and Luc- IGF1R -mu vectors. The sequences of the vectors were verified by DNA sequencing. A non-specific control luciferase vector, Luc-Ctrl was also constructed. All three vectors were co-transfected with $\beta$-galactosidase and miR-100 mimics (Ribo-Bio, Shanghai, China) into HEK293 cells in 6-well plates by using Lipofectamine 2000 according to the manufacturer's protocol. Twenty-four hours after transfection, the activity was assessed by a luciferase reporter assay system (Promega, USA) according to the manufacturer's recommendtaion. All luciferase activities were normalized to the $\beta$-galactosidase signal under luc-Ctrl condition.

\section{siRNA transfection}

The gene silencing IGF1R siRNA (IGF1R-siRNA) and non-specific control siRNA (NC-siRNA) were purchased from Stanta Cruz (Santa Cruz Biotechnology, USA). The transfection of siRNAs in RGC-5 cells was conducted with a Lipofectamine 2000 reagent according to manufacturer's recommendation. After reaching 50\% 60\% confluence, RGC-5 cells were transfected with IGF1RsiRNA $(100 \mathrm{nM})$ or NC-siRNA $(100 \mathrm{nM})$. The effect of siRNA on knocking down IGF1R protein, as well as other related proteins were examined by western blotting 48 hours after transfection.

\section{Statistical analysis}

All data were shown as the mean \pm S.E.M. For statistical analysis, a windows-based SPSS software was used. Comparison was made with student's $t$-test and the difference was termed to be significant if $P<0.05$. All experiments were conducted in triplicates.

\section{Results}

$\mathrm{H}_{2} \mathrm{O}_{2}$ induced apoptosis and upregulated miR-100 in RGC- 5 cells in a dose-dependent manner

First, we investigated the effect of oxidative stress on RGC-5 cell apoptosis. In our study, we cultured RGC-5 cells in 6-well plate for 24 hours, then included different concentration of $\mathrm{H}_{2} \mathrm{O}_{2}(100,200,400,500$ and $1000 \mu \mathrm{M})$ in RGC-5 cell culture for another 24 hours, followed by immunocytochemistry. The apoptosis was assessed by TUNEL assay. RGC-5 cells were identified by an antibody against Brn3a, a RGC-5 specific marker. Our results showed that $\mathrm{H}_{2} \mathrm{O}_{2}$ at the concentrations of 400 and $1000 \mu \mathrm{M}$ induced significant apoptosis among RGC-5 cells (Figure 2A). Further analysis by quantifying the percentage of TUNEL-positive cells among all Brn3a-positive RGC-5 cells revealed that the apoptosis in RGC-5 cells was induced by $\mathrm{H}_{2} \mathrm{O}_{2}$ in a dose dependent manner (Figure 2B, ${ }^{*}: P<0.05$ ). We then looked at the effect of $\mathrm{H}_{2} \mathrm{O}_{2}$-induced apoptosis on the expression level of miR-100 in RGC-5 cells. Our results demonstrated that miR-100 was significantly up-regulated, and also in a dose-dependent manner by the application of $\mathrm{H}_{2} \mathrm{O}_{2}$ in RGC-5 cells (Figure 2C, ${ }^{*}: P<0.05$ ).

\section{Downregulation of miR-100 reduces $\mathrm{H}_{2} \mathrm{O}_{2}$ induced apoptosis and promoted neurite growth in RGC- 5 cells} We then investigated whether miR-100 played a functional role in modulating $\mathrm{H}_{2} \mathrm{O}_{2}$-induced apoptosis in RGC-5 cells. For that purpose, we constructed lentiviral vector expressing the inhibitory oligonucleotides of miR100 (miR100-inhibitor) to specifically knock down the endogenous expression of miR-100. The efficiency of down-regulating miR-100 by lentivirus was verified by qRT-PCR. In that experiment, RGC-5 cells were transfected with either miR100-inhibitor, or its non-specific miRNA (miR-NC) for 24 hours. The results of qRT-PCR showed that the endogenous expression level of miR-100 was 
A

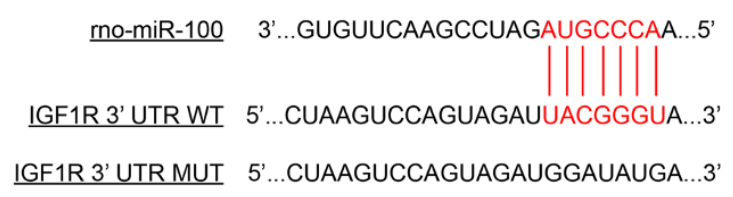

B

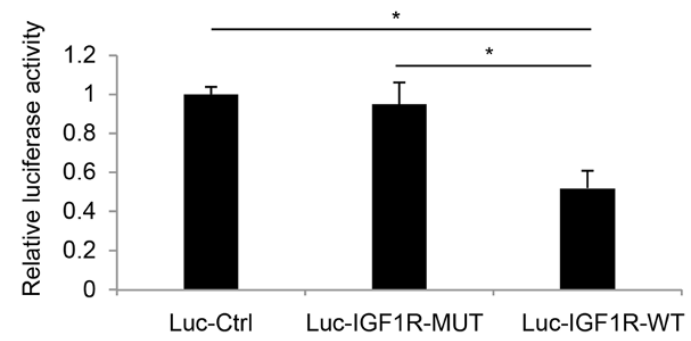

C

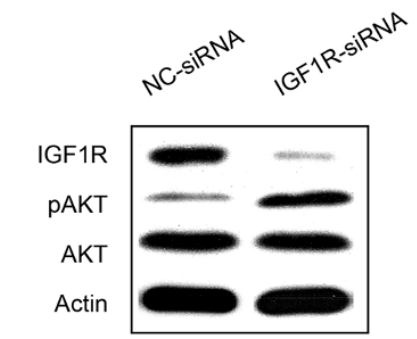

D

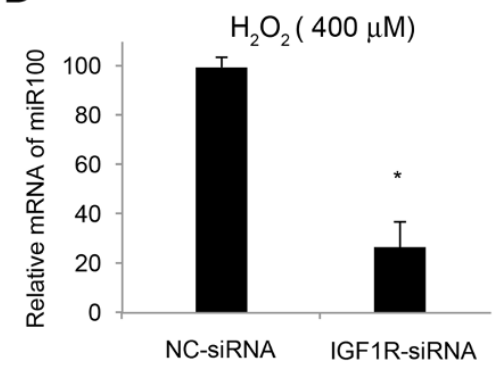

$E$

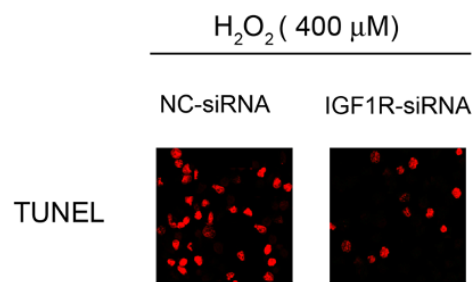

brn3a
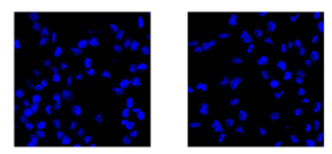

merge
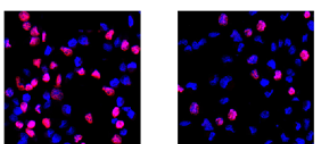

Figure 1 miR-100 interacted with IGF1R in RGC-5 cells. (A) Schematic diagram was shown for the predicted binding between rno-miR-100 and IGF1R 3'-UTR. The mutated 3'-UTR of IGF1R (IGF1R-mu) was also demonstrated. (B) In a luciferase report assay, HEK 293 T cells were transfected with pmiR-REPORT control vector (Luc-Ctrl), IGF1R vector with mutated 3'-UTR (Luc-IGF1R -mu) or IGF1R with wild-type 3'-UTR (Luc- IGF1R), along with $\beta$-galactosidase and miR-100 mimics for 24 hours. Luciferase signals were measured and normalized to the signal of control vector. (*: $P<0.05)$. (C) RGC-5 cells were treated with IGF1R-siRNA or its non-specific siRNA (NC-siRNA), followed by western blotting on AKT/pAKT and IGF1R in 48 hours. RGC-5 cells were pre-treated with IGF1R-siRNA (100 nM) or its non-specific siRNA (NC-siRNA, 100 nM) for 24 hours, followed by $\mathrm{H}_{2} \mathrm{O}_{2}(400 \mu \mathrm{M})$ treatment for another 24 hours. (D) The mRNA expression level of miR-100 was assessed by qRT-PCR (*: $P<0.05$ ). (E) RGC-5 apoptosis was assessed by TUNEL staining.

significantly and specifically down-regulated by miR100inhibitor (Figure 3A, ${ }^{*}: P<0.05$ ).

To evaluate the effect of down-regulating miR-100 on RGC- 5 apoptosis, we pre-treated RGC-5 cells with either miR100-inhibitor or miR-NC for 24 hours, followed by $\mathrm{H}_{2} \mathrm{O}_{2}(400 \mu \mathrm{M})$ treatment for another 24 hours. Our results of TUNEL staining showed that significantly less apoptosis were observed in miR-100 down-regulated RGC-5 cells than in control RGC-5 cells (Figure 3B). Quantification results demonstrated that the percentage of apoptotic cells reduced from $55.5 \%$ in control RGC-5 cells to around $30 \%$ in cells with miR-100 down-regulation (Figure 3C, ": $P<0.05$ ).

Interestingly, once the culture period was extended to 14 days after lentiviral transfection, we discovered 


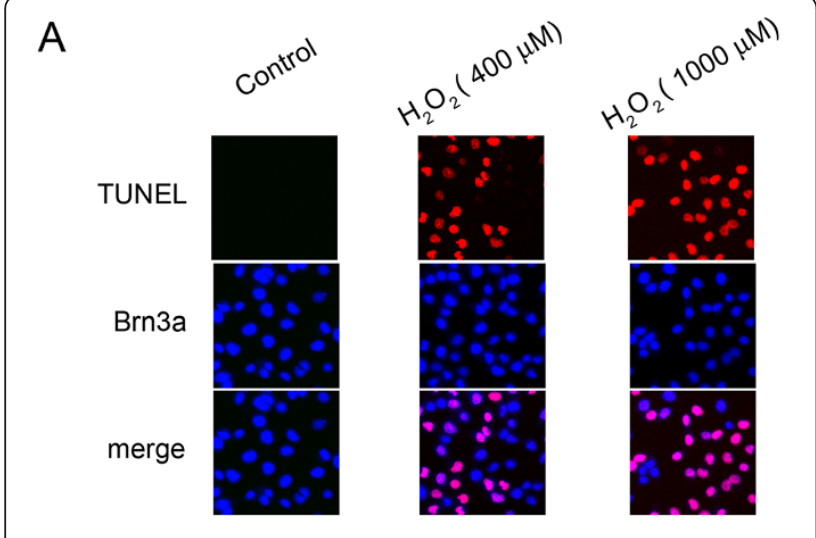

B
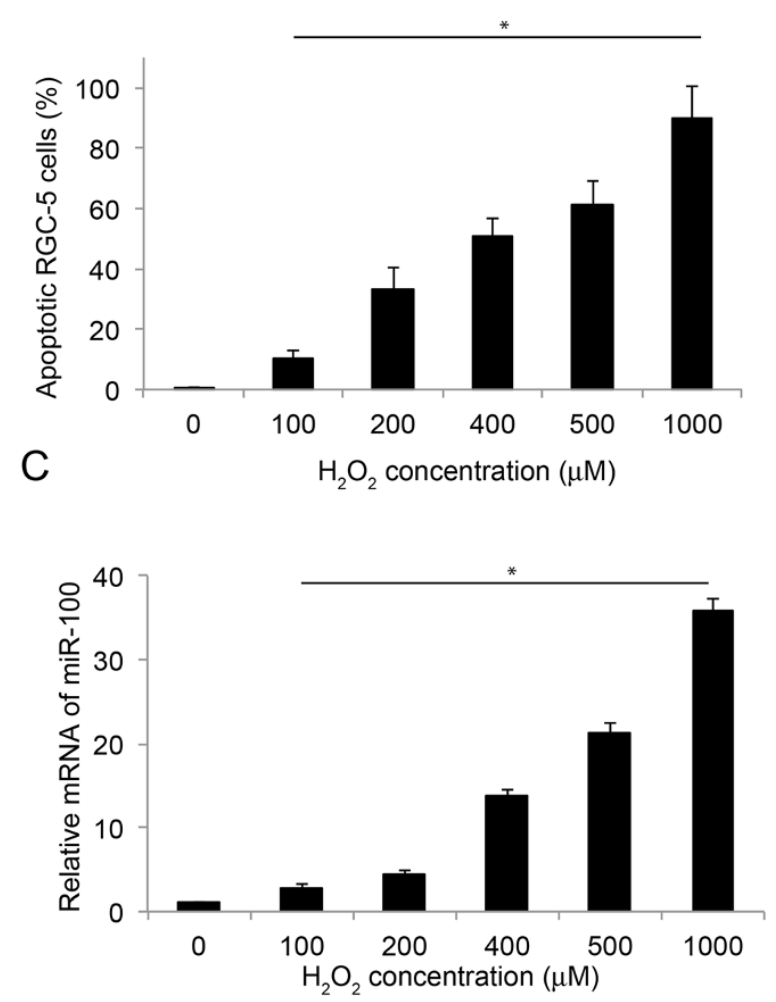

Figure $2 \mathrm{H}_{2} \mathrm{O}_{2}$ induced apoptosis and upregulated miR-100 in RGC- 5 cells. RGC -5 cells were treated with various concentrations of $\mathrm{H}_{2} \mathrm{O}_{2}$ for 24 hours to induce apoptosis. (A) Representative fluorescent images were shown for the untreated RGC-5 cells (control), and RGC-5 cells treated with $400 \mu \mathrm{M}$ or $1000 \mu \mathrm{M} \mathrm{H}_{2} \mathrm{O}_{2}$. An antibody against Brn3a (blue) was used to identify RGC-5 cells, and TUNEL staining was applied to identify apoptotic cells among them. (B) Quantification of the percentage of apoptotic RGC-5 cells (*: $P<0.05$, as compared to control). (C) The expression levels of miR-100, corresponding to the application of various concentrations $\mathrm{H}_{2} \mathrm{O}_{2}$, were measured by qRT-PCR (*: $P<0.05$, as compared to control).

that the morphology of RGC-5 cells was dramatically modified by miR-100 down-regulation. The RGC-5 cells with down-regulated miR-100 extended the peripherals to be long and neurite-like processes, whereas the cells without miR-100 downregulation kept original morphology of progenitor cell with short peripheral processes (Figure 4A). Quantitative measurement with ImagJ software (http://imagej.nih.gov/ij/) confirmed the effect of down-regulating miR-100 on promoting neurite length in RGC-5 cells (Figure 4B, *: $P<0.05$ ).

\section{Downregulation of miR-100 phosphorylated AKT/ERK/ TrkB pathways in RGC- 5 cells}

We then investigated the intracellular signaling pathways that might be involved in the protection of miR-100 down-regulation on RGC-5 apoptosis. In order to do that, RGC-5 cells were pre-treated with either miR100-inhibitor or miR-NC for 24 hours, followed by $\mathrm{H}_{2} \mathrm{O}_{2}(400 \mu \mathrm{M})$ treatment for another 24 hours. Western blotting analysis was used to measure the protein expression levels of Thy-1, ERK1/2, AKT and TrkB, as well as phosphorylation of ERK1/2, AKT and TrkB (Figure 5A). Our results demonstrated that down-regulating miR-100 did not alter the expression of Thy- 1 . However, miR-100 downregulation in RGC-5 cells significantly increased the phosphorylation in ERK1/2, AKT and TrkB, while keeping the total protein levels of ERK1/2, AKT and TrkB unchanged (Figure 5B-D, *: $P<0.05$ ).

\section{IGF1R was involved in miR-100 regulation in RGC-5}

Finally, we intended to explore the possible molecular target of miR-100 modulation in RGC-5 cells. Through online bioinformatic screening (Target Scan, http://www. targetscan.org/), we noticed that, insulin-like growth factor 1 receptor (IGF1R) was a likely target of rat miR-100 (Figure 1A). We thus applied a luciferase reporter assay to verify that miR-100 was directly binding IGF1R in RGC-5 cells (Figure 1B).

We then speculated IGF1R might be directly involved in the modulation of miR-100 on RGC-5 apoptosis. In order to examine that, we constructed siRNA to specifically knock down IGF1R gene in RGC-5 cells (IGF1R-siRNA). After applying $100 \mathrm{nM}$ IGF1R-siRNA or its non-specific control siRNA (NC-siRNA) in RGC-5 cells for 48 hours, we examined the knocking down efficiency by western blotting analysis. Our results showed that IGF1R protein was significantly reduced by IGF1R-siRNA (Figure 1C). The results also showed that down-regulation of IGF1R induced phosphorylation of AKT, whereas the total protein of AKT was unchanged (Figure 1C).

Finally, we examined the effect of knocking down IGF1R on miR-100 regulation and RGC-5 apoptosis. We pretreated RGC-5 cells with either IGF1R-siRNA (100 nM) or NC-siRNA (100 nM) for 24 hours, followed by $\mathrm{H}_{2} \mathrm{O}_{2}$ $(400 \mu \mathrm{M})$ treatment for another 24 hours. The results showed that the mRNA expression level of miR-100, presumably up-regulated upon apoptosis, was significantly down-regulated by knocking down IGF1R in RGC-5 cells 


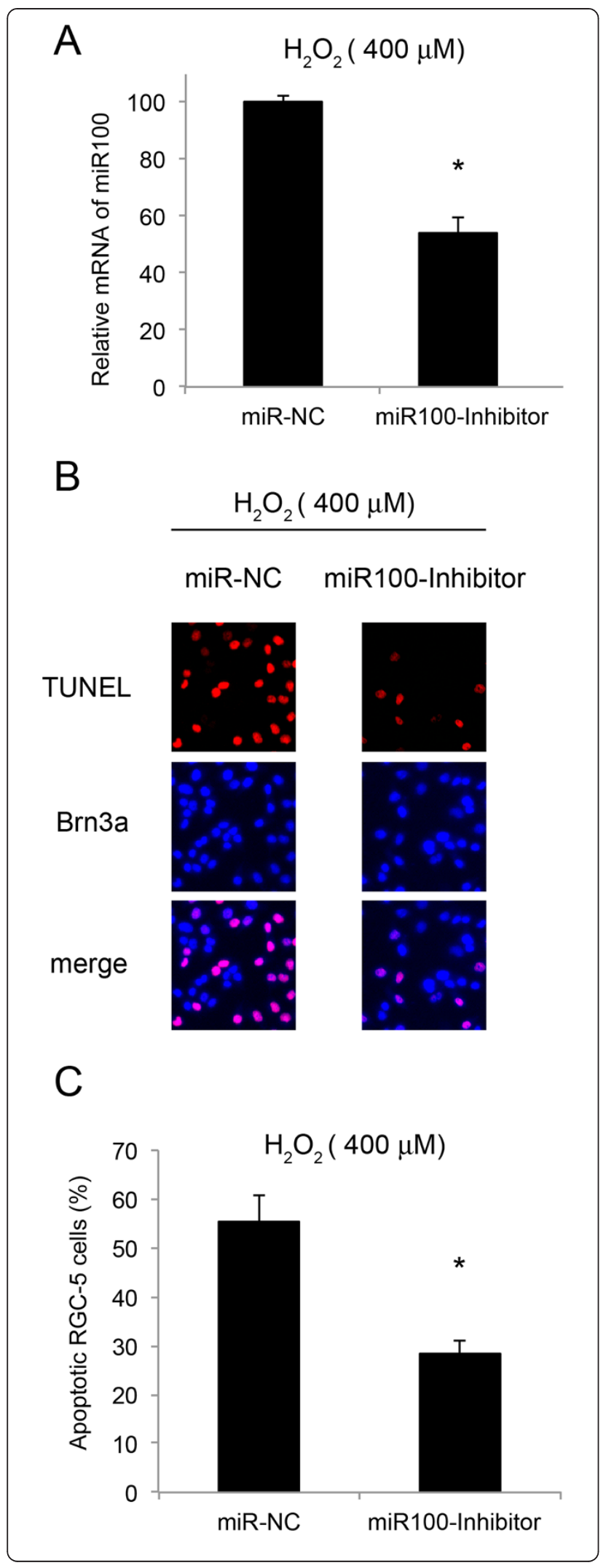

Figure 3 Downregulation of miR-100 protected apoptosis in RGC-5 cells. RGC-5 cells were pre-treated with lentiviral vector of miR100-inhibitor, or its non-specific miRNA vector (miR-NC) for 24 hours, followed by $\mathrm{H}_{2} \mathrm{O}_{2}(400 \mu \mathrm{M})$ treatment for another 24 hours. (A) The efficiency of down-regulating miR-100 by lentiviral vectors was evaluated by qRT-PCR (*: $P<0.05$ ). The effect of pre-treating RGC-5 cells with miR-100 down-regulation on oxidative stress induced apoptosis was then examined by TUNEL assay. (B) TUNEL staining was performed and representative fluorescent images were shown for the RGC-5 cells pre-treated with miR-NC, or miR100-inhibitor, and then $\mathrm{H}_{2} \mathrm{O}_{2} 400(\mu M)$. (C) The percentages of apoptotic RGC-5 cells were also quantified (*: $P<0.05$ ).

(Figure 1D). Moreover, the percentage of apoptotic RGC-5 was markedly reduced by knocking down IGF1R, from $78 \%$ to $33 \%$ (Figure $1 \mathrm{E}$ ).

\section{Discussion}

Oxidative stress has been suggested to be a major mechanism causing RGC degeneration [1], and the application of $\mathrm{H}_{2} \mathrm{O}_{2}$ is known to induce apoptosis among cultured RGCs. In the present study, we utilized an in vitro culture system to induce RGC-5 apoptosis through $\mathrm{H}_{2} \mathrm{O}_{2}$ and

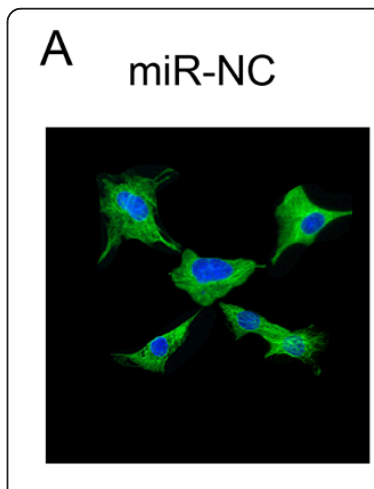

B

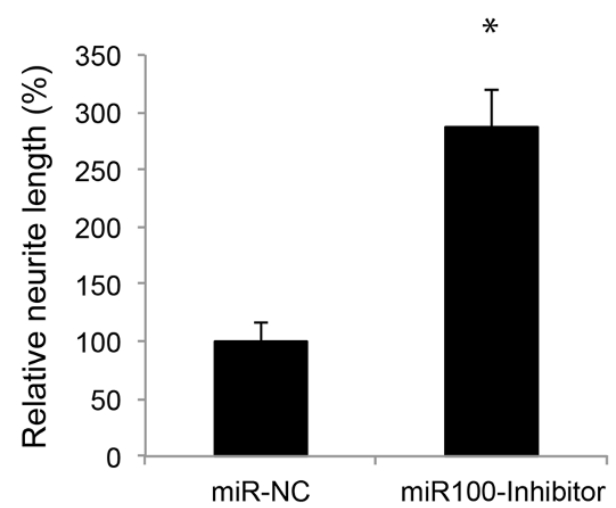

Figure 4 Downregulation of miR-100 promoted neurite growth in RGC-5 cells. (A) RGC-5 cells were treated with miR-NC or miR100inhibitor for 14 days, followed by immunostaining with an antibody against Thy-1 (green). DAPI (blue) staining was also performed. (B) Neurite lengths were measured using ImageJ software and compared between miR100-inhibitor treated RGC-5 cells and miR-NC treated RGC-5 cells $(*, P<0.05)$. 


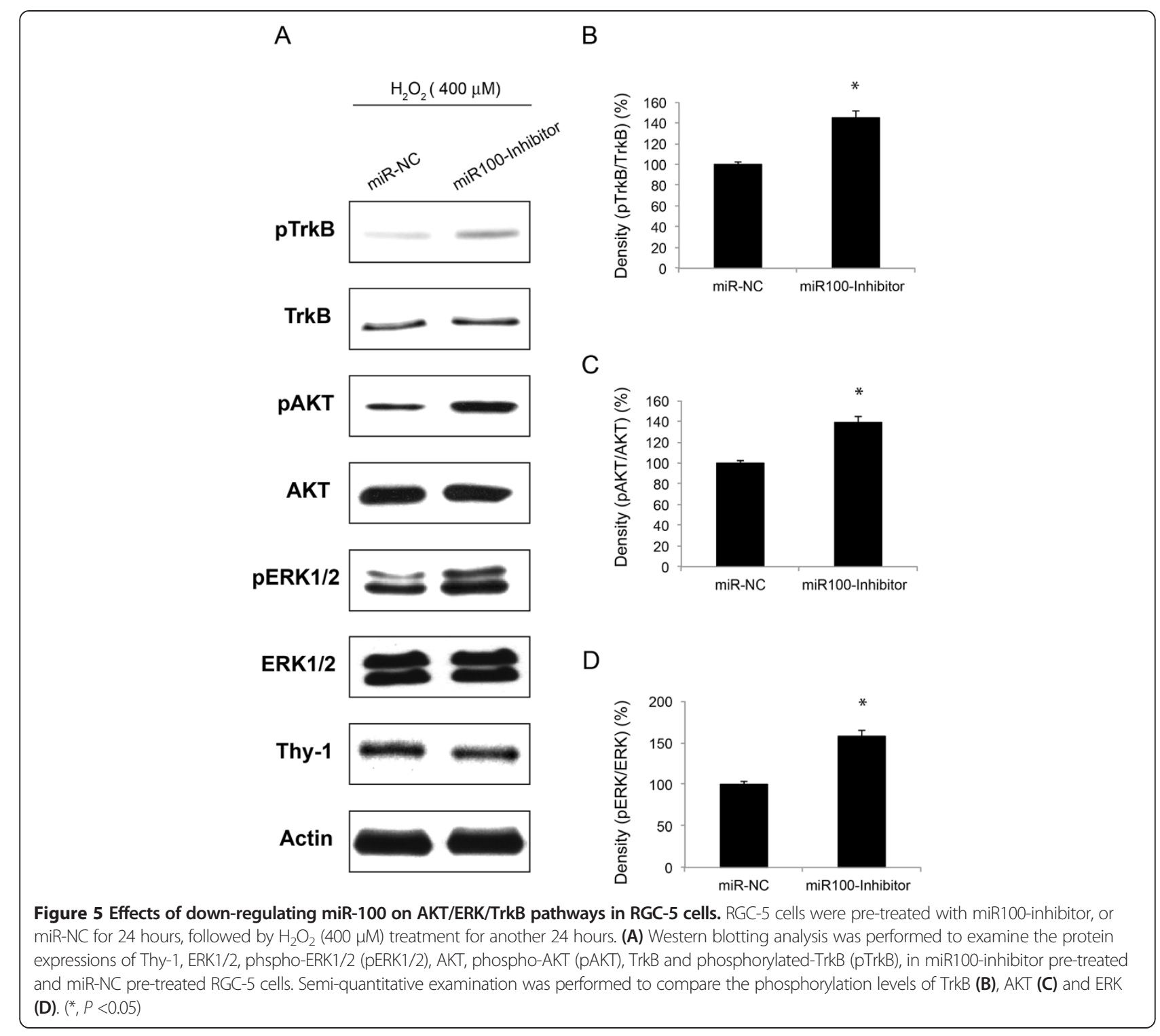

found that miR-100 was up-regulated by $\mathrm{H}_{2} \mathrm{O}_{2}$ in a dose-dependent manner. It has been commonly shown in the literature that miR-100 is an active factor in cancer regulation, modulating carcinoma development, metastasis or apoptosis [25,27]. In retina, though miR100 is expressed, little is known of its molecular mechanism [28]. In the present study, not only did we show an active change in expression profile of miR-100 upon $\mathrm{H}_{2} \mathrm{O}_{2}$-induced apoptosis, but we also demonstrated that down-regulation of miR-100 had a protective effect on RGC-5 apoptosis. Thus, these results highlighted a first ever report on functional role of miR-100 in retina.

Also in the present study we showed that, during $\mathrm{H}_{2} \mathrm{O}_{2}$-induced apoptosis, down-regulating miR-100 activated TrkB signaling pathways and its downstream Akt/ ERK pathways, through phosphorylation. Thus, it is likely that miR-100 downregulation may serve a role of TrkB agonist to exert a protective effect on $\mathrm{H}_{2} \mathrm{O}_{2}$-induced apoptosis in RGC-5 cells. This hypothesis was further supported by our results showing miR-100 down-regulation promoted neurite growth, possibly induced neural differentiation in RGC-5 cells, as TrkB activation is known to induce maturation in retina [29]. However, to elucidate the exact molecular interaction between miR-100 and TrkB/Akt/ERK pathways in protecting retinal ganglion apoptosis, future experiments of blocking TrkB or its downstream pathways upon the inhibition of miR-100 would provide solid evidence on direct targeting of miR100 on anti-apoptotic pathways in retinal ganglion cells.

Through online bioinformatics search, as well as our luciferase assay and functional experiments (Figure 1), we further revealed that IGF1R was very likely to be directly involved in the modulation of miR-100 on $\mathrm{H}_{2} \mathrm{O}_{2}$-induced apoptosis in RGC-5 cells. Furthermore, 
our results demonstrated that siRNA-mediated IGF1R knockdown activated Akt pathway and rescued $\mathrm{H}_{2} \mathrm{O}_{2}-$ induced apoptosis. This is consistent with previous study showing that IGF1R mutant mice had increased lifespan and significant resistance to oxidative stress in retinal ganglion cells [8]. Interestingly, our experiment also showed that knocking down IGF1R was able to down-regulate miR-100. This result suggests that, instead of being downstream target of miR-100, IGF1R might be mutually interacted with miR-100 in regulating $\mathrm{RGC}$ apoptosis, acting through miR-100 itself or its upstream pathways. Along with our early results demonstrating the functional association between miR-100 and Akt/ERK/ TrkB pathways, a much more complex molecular network might be involved in the regulation of miR-100 in retina.

\section{Conclusions}

Overall, our study identified a novel regulator, miR-100 in modulating apoptosis in retinal ganglion cells. The method of down-regulating miR-100 might help to further our understanding on the mechanisms of degeneration and regeneration in retina tissues.

\section{Competing interest}

The authors declare that they have no competing interest.

\section{Authors' contribution}

NK carried out the experiments and drafted manuscript. BL performed analysis. XL designed the study approved the final version of manuscript. All authors read and approved the final manuscript.

\section{Acknowledgements}

We thank Drs. Luli Zhang and Mingjie Song for their critical reviews of the manuscript.

\section{Author details}

'Department of Ophthalmology, Zhujiang Hospital, Southern Medical University, Guangzhou 510280, Guangdong Province, China. ${ }^{2}$ Department of Ophthalmology, Guangzhou Panyu Central Hospital, Guangzhou 510280, Guangdong Province, China.

Received: 3 August 2014 Accepted: 22 October 2014

Published online: 18 November 2014

\section{References}

1. Almasieh M, Wilson AM, Morquette B, Cueva Vargas JL, Di Polo A: The molecular basis of retinal ganglion cell death in glaucoma. Prog Retin Eye Res 2012, 31(2):152-181.

2. Tezel G: Oxidative stress in glaucomatous neurodegeneration: mechanisms and consequences. Prog Retin Eye Res 2006, 25(5):490-513.

3. Arjamaa O, Nikinmaa M: Oxygen-dependent diseases in the retina: role of hypoxia-inducible factors. Exp Eye Res 2006, 83(3):473-483.

4. Casson RJ: Possible role of excitotoxicity in the pathogenesis of glaucoma. Clin Experiment Ophthalmol 2006, 34(1):54-63.

5. Kanamori A, Nakamura M, Nakanishi Y, Nagai A, Mukuno H, Yamada Y, Negi A: Akt is activated via insulin/IGF-1 receptor in rat retina with episcleral vein cauterization. Brain Res 2004, 1022(1-2):195-204.

6. Kermer P, Klocker N, Labes M, Bahr M: Insulin-like growth factor-I protects axotomized rat retinal ganglion cells from secondary death via PI3-Kdependent Akt phosphorylation and inhibition of caspase- 3 In vivo. J Neurosci 2000, 20(2):2-8.

7. Averbukh E, Weiss O, Halpert M, Yanko R, Moshe R, Nephesh I, Flyvbjerg A, Yanko L, Raz I: Gene expression of insulin-like growth factor-l, its receptor and binding proteins in retina under hypoxic conditions. Metab Clin Exp 1998, 47(11):1331-1336.

8. Holzenberger M, Dupont J, Ducos B, Leneuve P, Geloen A, Even PC, Cervera $P$, Le Bouc Y: IGF-1 receptor regulates lifespan and resistance to oxidative stress in mice. Nature 2003, 421(6919):182-187.

9. Klocker N, Kermer P, Weishaupt JH, Labes M, Ankerhold R, Bahr M: Brain-derived neurotrophic factor-mediated neuroprotection of adult rat retinal ganglion cells in vivo does not exclusively depend on phosphatidyl-inositol-3'-kinase/ protein kinase B signaling. J Neurosci 2000, 20(18):6962-6967.

10. Kilic U, Kilic E, Jarve A, Guo Z, Spudich A, Bieber K, Barzena U, Bassetti CL, Marti HH, Hermann DM: Human vascular endothelial growth factor protects axotomized retinal ganglion cells in vivo by activating ERK-1/2 and Akt pathways. J Neurosci 2006, 26(48):12439-12446.

11. Tong M, Brugeaud A, Edge AS: Regenerated synapses between postnatal hair cells and auditory neurons. J Assoc Res Otolanyngol 2013, 14(3):321-329.

12. Koeberle PD, Tura A, Tassew NG, Schlichter LC, Monnier PP: The repulsive guidance molecule, RGMa, promotes retinal ganglion cell survival in vitro and in vivo. Neuroscience 2010, 169(1):495-504.

13. Brugeaud A, Tong M, Luo L, Edge AS: Inhibition of repulsive guidance molecule, RGMa, increases afferent synapse formation with auditory hair cells. Dev Neurobiol 2014, 74(4):457-466.

14. Pernet V, Schwab ME: Lost in the jungle: new hurdles for optic nerve axon regeneration. Trends Neurosci 2014, 37(7):381-387.

15. Pillai RS: MicroRNA function: multiple mechanisms for a tiny RNA? RNA 2005, 11(12):1753-1761.

16. Lumayag S, Haldin CE, Corbett NJ, Wahlin KJ, Cowan C, Turturro S, Larsen PE, Kovacs B, Witmer PD, Valle D, Zack DJ, Nicholson DA, Xu S: Inactivation of the microRNA-183/96/182 cluster results in syndromic retinal degeneration. Proc Natl Acad Sci U S A 2013, 110(6):E507-E516.

17. Zhu Q, Sun W, Okano K, Chen Y, Zhang N, Maeda T, Palczewski K: Sponge transgenic mouse model reveals important roles for the microRNA-183 (miR-183)/96/182 cluster in postmitotic photoreceptors of the retina. J Biol Chem 2011, 286(36):31749-31760.

18. Remenyi J, van den Bosch MW, Palygin O, Mistry RB, McKenzie C, Macdonald A, Hutvagner G, Arthur JS, Frenguelli BG, Pankratov Y: miR-132/ 212 knockout mice reveal roles for these miRNAs in regulating cortical synaptic transmission and plasticity. PLoS One 2013, 8(4):e62509.

19. Sanuki R, Onishi A, Koike C, Muramatsu R, Watanabe S, Muranishi Y, Irie S, Uneo S, Koyasu T, Matsui R, Cherasse Y, Urade Y, Watanabe D, Kondo M, Yamashita T, Furukawa T: miR-124a is required for hippocampal axogenesis and retinal cone survival through Lhx2 suppression. Nat Neurosci 2011, 14(9):1125-1134.

20. Small EM, Sutherland LB, Rajagopalan KN, Wang S, Olson EN: MicroRNA-218 regulates vascular patterning by modulation of Slit-Robo signaling. Circ Res 2010, 107(11):1336-1344.

21. Marler KJ, Suetterlin P, Dopplapudi A, Rubikaite A, Adnan J, Maiorano NA, Lowe AS, Thompson ID, Pathania M, Bordey A, Fulga T, Van Vactor DL, Hindges $R$, Drescher $U$ : BDNF promotes axon branching of retinal ganglion cells via miRNA-132 and p250GAP. J Neurosci 2014, 34(3):969-979.

22. Loscher CJ, Hokamp K, Wilson JH, Li T, Humphries P, Farrar GJ, Palfi A: A common microRNA signature in mouse models of retinal degeneration. Exp Eye Res 2008, 87(6):529-534

23. Loscher CJ, Hokamp K, Kenna PF, Ivens AC, Humphries P, Palfi A, Farrar GJ: Altered retinal microRNA expression profile in a mouse model of retinitis pigmentosa. Genome Biol 2007, 8(11):R248.

24. Nagaraja AK, Creighton CJ, Yu Z, Zhu H, Gunaratne PH, Reid JG, Olokpa E, Itamochi H, Ueno NT, Hawkins SM, Anderson ML, Matzuk MM: A link between mir-100 and FRAP1/mTOR in clear cell ovarian cancer. Mol Endocrinol 2010, 24(2):447-463.

25. Shi W, Alajez NM, Bastianutto C, Hui AB, Mocanu JD, Ito E, Busson P, Lo KW, $\mathrm{Ng} \mathrm{R}$, Waldron J, O'Sullivan B, Liu FF: Significance of Plk1 regulation by miR-100 in human nasopharyngeal cancer. Int J Cancer 2010, 126(9):2036-2048.

26. Kovacs B, Lumayag S, Cowan C, Xu S: MicroRNAs in early diabetic retinopathy in streptozotocin-induced diabetic rats. Invest Ophthalmol Vis Sci 2011, 52(7):4402-4409.

27. Leite KR, Sousa-Canavez JM, Reis ST, Tomiyama AH, Camara-Lopes LH, Sanudo A, Antunes AA, Srougi M: Change in expression of miR-let7c, miR-100, and miR-218 from high grade localized prostate cancer to metastasis. Urol Oncol 2011, 29(3):265-269. 
28. Hackler L Jr, Wan J, Swaroop A, Qian J, Zack DJ: MicroRNA profile of the developing mouse retina. Invest Ophthalmol Vis Sci 2010, 51(4):1823-1831.

29. Rohrer B, Korenbrot JI, LaVail MM, Reichardt LF, Xu B: Role of neurotrophin receptor TrkB in the maturation of rod photoreceptors and establishment of synaptic transmission to the inner retina. J Neurosci 1999, 19(20):8919-8930.

doi:10.1186/s12867-014-0025-1

Cite this article as: Kong et al:: Downregulation of microRNA-100 protects apoptosis and promotes neuronal growth in retinal ganglion cells. BMC

Molecular Biology 2014 15:25.

\section{Submit your next manuscript to BioMed Central and take full advantage of:}

- Convenient online submission

- Thorough peer review

- No space constraints or color figure charges

- Immediate publication on acceptance

- Inclusion in PubMed, CAS, Scopus and Google Scholar

- Research which is freely available for redistribution 